\title{
Bolhas de verdade: cinco alfinetes para (re)construir a democracia
}

\author{
Maria João Silveirinha \\ Universidade de Coimbra / ICNova \\ E-mail: mjsilveirinha@hotmail.com
}

\begin{abstract}
Resumo
No nosso artigo procuramos refletir sobre as implicações que o termo "pós-verdade" tem como forma de caracterizar as nossas sociedades com um malestar mediático, cultural, social e político. Consideramos que a importante investigação que se tem produzido sobre o tema e que o liga à cultura mediática deve alargar o seu âmbito para além dos media

do populismo e das suas fórmulas que dão sustentação aos movimentos de ultra-direita que ressurgem nos nossos horizontes democráticos. Para o efeito, consideramos cinco elementos - a que chamamos bolhas de verdade - para sinalizar algumas perspetivas que consideramos críticas sobre o que está em causa nesta problemática.
\end{abstract} se queremos compreender o avanço sem precedentes

Palavras-chave: pós-verdade; distopias; pós-modernidade; populismo.

\begin{abstract}
In our article we seek to reflect on the implications of the word "post-truth"as a way of characterizing our societies suffering from a media, cultural, social and political malaise. We believe that the important research that has already been produced on this issue linking it to the media culture should extend its

unprecedented advance of populism and its formulas that support ultra-right movements which have resurface our democratic horizons. To this end, we consider five elements - what we call truth bubbles - to signal a number of perspectives which we consider critical to understand what is at stake.
\end{abstract} scope beyond the media in order to understand the

Keywords: post-truth; dystopia; post-modernism; populism.

\section{Introdução}

А OFICIALIZAÇ̃̃o do termo "pós-verdade" pelo dicionário de Oxford no ano de 2016 não teria uma importância significativa se ela não resultasse da grande frequência da sua utilização

Data de submissão: 31/05/2017. Data de aprovação: 30/06/2017.

A Revista Estudos em Comunicação é financiada por Fundos FEDER através do Programa Operacional Factores de Competitividade - COMPETE e por Fundos Nacionais através da FCT - Fundação para a Ciência e a Tecnologia no âmbito do projeto Comunicação, Filosofia e Humanidades (LabCom.IFP) UID/CCI/00661/2013.
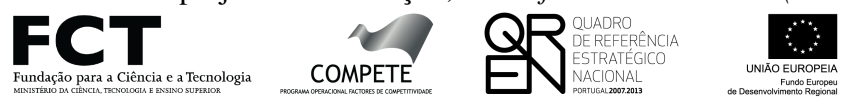

1) 
durante dois eventos políticos particularmente relevantes nesse mesmo ano: o referendo que levou à saída da Grã-Bretanha da União Europeia e as eleições americanas que ditaram a vitória de Donald Trump. Estes acontecimentos, que foram sendo seguidos por outros que demonstravam a ascensão de políticas populistas um pouco por todo o mundo, provocaram um forte mal-estar em torno dos problemas do défice democrático, cuja responsabilidade foi, muitas vezes, atribuída aos media. Com efeito, o discurso da pós-verdade compreende vários ângulos de crítica relacionada com os media: a perda do monopólio da mediação do jornalismo e as alterações na dinâmica do consumo de notícias; os efeitos de exclusão da bolha dos media sociais; o funcionamento ideológico das organizações noticiosas; o efeito de fórmulas algorítmicas de ditar o consumo de informações e a desconfiança dos peritos. Todas estas questões têm sido amplamente tratadas na investigação da comunicação e dos media.

Defendo, porém, que essa mesma investigação deve alargar o seu âmbito para além dos media se queremos compreender o avanço sem precedentes do populismo e das suas fórmulas de "pós-verdade" que dão sustentação a movimentos de ultra-direita. Na verdade, é altamente redutor responsabilizar unicamente os media por todo este mal-estar, desconsiderando os intrincados e antigos fatores educacionais, económicos, sociais, culturais e religiosos que influenciam a consciência política e de compromisso. O discurso e a cultura da pós-verdade, bem como o mal-estar que lhes está associado, é um fenómeno multidimensional que precisa de ser discutido de forma a, por um lado, discernir os vários elementos que o compõem e, por outro, integrar estes elementos de forma coerente. No que se segue, procurarei juntar mais algumas perspetivas a toda esta complexa e difícil situação ético-política e comunicacional em que nos encontramos, analisando cinco elementos - a que chamo bolhas de verdade - que, na minha expectativa, ajudarão também a lançar luz sobre o que está em causa nesta problemática.

\section{A bolha das distopias da verdade}

Começo por recordar que publicado em 1948, o livro de George Orwell 1984 passou para topo da lista dos livros mais vendidos depois de Donald Trump ter tomado posse. É que a distopia de Orwell visava as ditaduras totalitárias que procuravam manter o poder pela censura de vozes discordantes, pelo controlo da informação e pela asserção de uma versão única e centralizada da verdade.

Mas uma outra distopia parece mais adequada aos perigos que vemos irromper nas nossas democracias: a de Aldous Huxley O Admirável Nundo Novo, publicada em 1932. Andrew Postman (2017) recordava isso mesmo num artigo publicado no The Guardian. O livro de seu pai, Neil Postman, contrastara em 1985 estas duas visões distópicas, para mostrar como O Admirável Mundo Novo se adequava melhor à sociedade da televisão. Para Postman, uma frase escrita podia ser, a algum nível, verificável: é verdadeira ou não, ou pelo menos, podemos discuti-la. Não a imagem: nunca discutimos uma imagem como sendo verdadeira ou falsa - apenas em que medida ela capta a nossa atenção. E Andrew Postman (2017) relembra: "Esta era, em espírito, a visão que Huxley previu em 1931, a distopia sobre a qual o meu pai acreditava que devíamos ter cuidado".

Relendo Amusing Ourselves to Death, o contraste que Postman faz entre as duas distopias uma de ataque às ditaduras, outra sobre os perigos de que a democracia padece - faz, para mim, um 
sentido que talvez não tivesse feito quando li a obra pela primeira vez. Diz Postman (2005: xix): "Orwell temia aqueles que nos privariam de informação. Huxley, aqueles que nos dariam tanta que seríamos reduzidos à passividade e ao egoísmo. Orwell temia que a verdade fosse escondida de nós. Huxley, que fosse afogada num mar de irrelevância". No universo de Huxley, cada vez que as massas tomavam o poder público, era a felicidade, mais que a verdade, o que importava. A verdade era considerada uma ameaça. Mas não era necessário um esforço totalitário para controlar as massas e impedi-las de procurarem uma outra verdade. Todos aceitavam as ideias disseminadas de bom grado pois, afinal de contas, o que estava em causa não era a verdade, mas a felicidade.

Podemos ainda associar aos tempos que vivemos uma terceira distopia: aquela que Margaret Atwood nos apresenta no seu livro de 1985, The Handmaid's Tale (Atwood, 1885//2013), recentemente adaptado a uma série televisiva. Concentrando a narrativa numa personagem feminina central, Atwood revela a indignidade e o terror de viver sob um regime futurista controlado por fundamentalistas cristãos, chamado Gileade. A heroína é uma das várias "servas"que, por terem "ovários viáveis", são confinadas a um campus de prisão onde se limitam a ficar disponíveis para terem relações sexuais periodicamente programadas com seus "Comandantes da Fé". O estado em Gileade prescreve um padrão de vida baseado na frugalidade, conformidade, censura, corrupção, medo e terror e mantém seu poder por meio de vigilância disseminada, supressão de informação, centros de "reeducação"e violência totalitária - em suma, os termos habituais de existência impostos por estados totalitários, como encontramos no Admirável Mundo Novo de Huxley ou em 1984 de Orwell.

Como nos diz Edward H. Howell (2009), The Handmaid's Tale concentra-se e força os seus leitores a reconhecer a importância da "atenção contínua"à situação cultural e comunicativa da sua narradora, uma mulher que, em última instância, se recusa a permanecer em silêncio. O lugar de onde fala esta narradora, Offred, define o sentido que a cultura que vive lhe atribui: a sua própria existência só tem sentido a medida em que este reside unicamente no seu corpo biológico de mulher e na sua capacidade de reprodução. Em termos práticos, isto acontece porque o Estado padece de uma profunda crise de esterilidade consequente da poluição nuclear e química. E, ainda como diz Howell (2009), sendo o corpo de Offred definido pelos que estão no poder, o seu significado e valor são paradoxalmente construídos através de uma correlação com a "Natureza". No Estado político em causa, os dispositivos tecnológicos existentes são mínimos e o exercício de vigilância absoluta faz-se por mecanismos panóticos de inculcação do sentido de ser vigiada. Nesse contexto, a mediação da consciência ou identidade da personagem principal é construída pelos outros e por si mesma nos atos de linguagem e de nomeação: Offred narra a sua história e o seu corpo dócil é reconstruído por esta mesma narração. No livro, não chegamos nunca a saber o seu nome verdadeiro (preservado como a única verdade sobre a heroína?), não chegamos nunca a conhecer a verdade do seu destino final.

Stein (2001: 138) faz notar que as camadas textuais que existem na narrativa servem para problematizar a noção do reino totalitário de Gilead de que existe uma única verdade - a versão oficialmente sancionada -, mas a narração da sua heroína remete-nos para as formas como se chegou a essa "verdade": 
"Nós vivíamos ignorando. Ignorar não é o mesmo que a ignorância, pois implica um esforço

(...) Havia histórias nos jornais, é claro, cadáveres em valas ou bosques, mortos ou mutilados (...), mas as notícias eram sobre outras mulheres, e os homens que faziam essas coisas eram outros homens. (...) Vivíamos no espaço entre as notícias"(Atwood, 1885/2013: 53).

É aí, possivelmente, que reside a explicação pela qual a distopia de Atwood parece ser perigosamente atual, trinta anos após ter sido escrita. Mas há, no nosso entendimento, outros elementos nesta distopia de Margaret Atwood que desenham os limites do seu feminismo e se aliam ao pósmodernismo. Como refere Fiona Tolan,

"Tendo por pano de fundo o debate da pós-modernidade, os meados de 1980 tornaram-se um ponto de avaliação e reinvenção do feminismo (...).The Handmaid's Tale olha para esta transição (...). Atwood expõe a natureza limitadora e prescritiva do utopismo que sustentou grande parte do feminismo da segunda vaga inicial. Ao justapor flashbacks do ativismo feminista das décadas de 1970 com descrições contemporâneas das práticas de Gileade, ambos se constituem mutuamente, de modo que The Handmaid's Tale retrata satiricamente uma sociedade distópica que, inconsciente e paradoxalmente, conheceu certos objetivos feministas"(2007: 145).

Entre os fantasmas de vigilância Orwelliana, a estupidificação em massa Huxliana ou Postmaniana ou ainda a opressão física e discursiva da identidade proposta por Atwood, vemos desenhada a nossa segunda bolha: a dos paradoxos pós-modernos.

\section{A bolha dos paradoxos pós-modernos}

Simplificando uma questão que é certamente mais complexa do que podemos aqui explorar, podemos dizer que os pós-modernos, de uma forma geral, ao iniciarem um prolongado ataque às pretensões científicas das ciências sociais, colocaram em destaque a oposição conceptual entre "verdadeiro" e "falso", argumentando que esta diferenciação binária é apenas o resultado de uma Razão autorreferencial idiossincrática.

Assim, o que foi posto em causa foi o próprio projeto moderno de Razão, enquanto força capacitadora que permite aos sujeitos, dotados de reflexão crítica e de capacidade de representação linguística, procurar verdades objetivas e, desse modo, assegurar a sua emancipação. Numa condição pós-moderna, temos de nos libertar das categorias binárias (como verdadeiro/falso), confrontarnos com o carácter ilusório da busca pela verdade e com o facto de que, na medida em que toda a realidade humana é construída, o conhecimento é relacionalmente contingente. Ou, dito de outra forma, temos de nos confrontar com a relatividade intrínseca de todas as formas de conhecimento. Qualquer afirmação de verdade é apenas uma versão desta, o que significa que há uma enorme multiplicidade de verdades relacionalmente construídas. Como diz Bauman:

"A verdade é, em outras palavras, uma relação social (como poder, propriedade ou liberdade): um aspeto de uma hierarquia feita de unidades de superioridade e inferioridade; mais precisamente, um aspeto da forma hegemónica de dominação ou de uma pretensão a dominar pela hegemonia. (Bauman, 1999: 245-246). 
$\mathrm{O}$ associado ataque às ambições universalistas de discursos de emancipação ou às grandes narrativas que residem no centro do projeto Iluminista (Lyotard, 1989) implica, portanto, que já não há necessidade de produzir "a verdade"porque há muitas verdades, dependendo da própria identidade e subjetividade. A acrescer, os avanços nas tecnologias de comunicação ter-nos-iam deixado numa hiper-realidade ou num real sem origem ou realidade, que não nos permite distinguir entre o real e o falso (Baudrillard, 1991/1981.).

O paradoxo da condição pós-moderna é que, ao colocar todos os princípios sob o escrutínio do seu ceticismo, nem mesmo os seus próprios princípios ficam além do questionamento. Mas o paradoxo estende-se ao facto de que, na verdade, o desembaraçar pós-moderno de todas as dicotomias e binarismos (como verdadeiro/falso, certo/errado, etc.) não consegue resolver a necessidade de distinguirmos precisamente entre estas categorias, uma vez que ficamos sem qualquer critério epistémico que nos permita essa distinção.

As consequências destes pressupostos geraram também tensões entre a política moderna e as políticas pós-modernas, não apenas na equação "verdade versus conhecimento contingente" como no par "igualdade-diferença".

Os dois polos pós-modernos destas tensões foram, de facto, inspiradores para alguns movimentos sociais, interessados na exploração e construção de realidades sociais radicalmente contingentes, abertas e múltiplas, produzindo o que genericamente se designa por "políticas de identidade" ou "políticas do reconhecimento". O terreno comum entre estas políticas e o pós-modernismo é o seu ceticismo do princípio da universalidade, a que se opõe a diferença e a celebração das particularidades da experiência, o que é claramente confuso para quem insiste em que a base de toda a ação comum é precisamente a universalidade da opressão (mesmo que esta não tenha a mesma dimensão para todas/os). Habermas descreve a nossa confusão do seguinte modo: "Quando os recipientes de uma esfera cultural desenvolvida de forma autónoma se quebram, o conteúdo dispersa-se. Nada resta de um significado de-sublimado ou de uma forma desestruturada: daí não se segue um efeito emancipatório" (Habermas 1981: 10).

Também Nancy Fraser nos tem vindo a avisar desde há muito tempo que tanto a nossa prioridade com a questão das identidades e do reconhecimento correm o risco de servir as lógicas neo-liberais que nos oprimem. Mais contundentemente (2016), e falando especificamente das políticas que têm dividido as feministas, afirma que estas devem recusar escolher entre "o neoliberalismo progressista" e o "populismo reacionário", "tendo de reconhecer o seu quinhão de culpa ao sacrificarem a causa da proteção social, bem-estar material e a dignidade da classe trabalhadora em função de falsos entendimentos da emancipação em termos de meritocracia, diversidade e capacitação" (Fraser, 2016: 283).

\section{A bolha do poder bruto}

"Cada sociedade tem seu regime de verdade, sua "política geral' de verdade", afirmou Foucault. "Isto é", continuava ele, "os tipos de discurso que aceita e faz funcionar como verdadeiro; os mecanismos e instâncias que permitem distinguir afirmações verdadeiras e falsas, os meios pelos quais cada uma é sancionada; as técnicas e procedimentos a que é reconhecido valor na aquisição da verdade; o status daqueles que são encarregados de dizer o que conta como verda- 
deiro" (Foucault, 1976/2000, p. 130). Mas Foucault descreve também nas primeiras páginas de Vigiar e Punir um exercício de "poder bruto" sobre o corpo de um condenado. Os instrumentos de tortura são detalhados e sentimos o corpo supliciado. Esse corpo, diz Foucault, desapareceu, para ser substituído por um corpo inteiramente vigiado e punido com sobriedade. Mas no poder a que somos hoje (violentamente) sujeitas pelos sistemas de vigilância tecnológica, no vácuo de uma normatividade comum, tais sistemas servem inteiramente aquilo que Foucault viu ultrapassado por outros tipos de poder: o poder "bruto". Neste poder bruto, se não há tortura física, há um outro tipo de tortura: o facto de termos de viver de modo inquestionável a versão de verdade que prevalece como a do mais forte, mesmo que os tradicionais "vigias" do poder (os media) a tentem desmontar. Sob o poder bruto, a tortura instala-se na nossa tentativa de fazermos sentido de um mundo onde domina a ostentação da falsidade e a ausência da necessidade de provar os factos e de assumir responsabilidade pelo que se diz; onde a "dupla moral" das distopias de que falámos acima se impõe. Os vários Trumps que vão pululando no terreno cada vez mais pantanoso da nossa democracia tomam os media como seu alvo e invertem a acusação de falsidade, alterizando a mentira, transformando os media num "eles" (falsos) que o "nós" dos poderosos podem destruir com a força do mais forte.

James Fallows (2012) cedo apontou a dificuldade da imprensa mainstream em lidar com a "política da pós-verdade". Mais recentemente (2017) afirmou que "O momento Trump promoveu a ideia de que não há factos, nem realidade, nem autoridades, nem verdade real. Só nós e eles".

Esta dicotomia de "accountability" invertida gera uma profunda crise dos media que, associada a uma profunda crise da confiança dos valores da solidariedade e do diálogo, cria a enorme bolha do poder discursivo da direita racista, sexista e xenófoba que vemos crescer todos os dias.

No atual clima político, a verdade é, assim, substituída por argumentos demonstrativos que apelam ao eleitorado a um nível não racional, mas visceral e das emoções negativas. O discurso político da pós-verdade é caracterizado por uma cegueira voluntária à evidência, uma desconfiança da autoridade, e um apelo a argumentos enraizados em medos ou ansiedades. Neste clima, o consenso que, como sempre nos disse Habermas, é o fundamento da democracia, parece impossível. E, no entanto, para que as profundas diferenças económicas e culturais que nos dividem sejam resolvidas de forma devidamente democrática, é necessário que haja acordo sobre os termos do debate. Mas, quando os atores políticos não conseguem concordar com factos e procedimentos básicos, a argumentação de compromisso é basicamente impossível. Nesse momento, está criado o vazio que os factos alternativos ocupam, devolvendo a política a uma luta de poder bruto, na qual os mais fracos são dominados pelos mais fortes.

\section{A bolha da tecnologia}

O discurso da pós-verdade é também evocativo de preocupações já conhecidas ligadas ao pensamento que interroga como a tecnologia da comunicação alterou não só o que sabemos, mas como o conhecimento é construído, a forma como nos ligamos uns aos outros e a nossa relação com as estruturas sociais; e, de facto, importa questionar a promessa utópica da Internet como uma esfera pública global e o seu impacto sobre as formas como a experiência humana e expressão cultural têm sido fundamentalmente reconfiguradas pelas tecnologias de comunicação informatizadas. 
Como vários autores têm sugerido, as pessoas crescentemente vivem na sua própria bolha de conteúdo criada pela personalização dos algoritmos dos media sociais, que nos alimentam com o conteúdo com que estamos em sintonia, e filtramos conteúdo com que podemos não concordar, ou simplesmente achar desinteressante.

A ideia da bolha de filtros (Pariser, 2011) existe há algum tempo e faz eco de ideias anteriores da Internet como uma câmara de eco (Sunstein, 2001) em que as nossas opiniões são simplesmente repetidas ao infinito. Habermas (2006: 423), mesmo que como "nota de passagem" e na forma de nota de roda-pé, já previu o seu perigo há mais de 10 anos: "O surgimento de milhões de chatrooms fragmentadas por todo o mundo tende a conduzir à fragmentação dos públicos de massa, grandes, mas politicamente focados, numa grande quantidade de questões públicas isoladas".

Talvez a apreciação mereça o lugar de nota-de-rodapé. De certa forma, bolha de filtros e câmaras de eco são metáforas úteis não apenas para chamar a atenção para o seu forte potencial fragmentador, como para as sombras narcisistas dos media sociais. Mas por outro lado, enfatizam excessivamente o papel da tecnologia na mediação das relações sociais e atribuem níveis irracionais de poder e eficácia aos processos algorítmicos. Além disso, se os media sociais absorveram as notícias, ameaçando o financiamento de relatórios de interesse público e inaugurando uma era em que todos têm os seus próprios factos, $\mathrm{s}$ consequências vão muito além dos media. Isso mesmo vemos na apreciação de Habermas, que voltamos a citar, sobre o estado das empresas jornalísticas:

"Quando a reorganização e o corte de custos prejudicam os padrões habituais de jornalismo, atingem o cerne da esfera pública política. Porque, sem o fluxo de informações obtidas através de uma extensa pesquisa, e sem o estímulo de argumentos baseados numa experiência que não é barata, a comunicação pública perde sua vitalidade discursiva. Os media públicos deixam de resistir às tendências populistas e não podem cumprir a sua função no contexto de um Estado constitucional democrático “ (Habermas, 2007).

A compreensão do que está em causa é, pois, fundamental e para isso precisamos de sair das nossas bolhas para olharmos o fluido onde elas circulam - a Rede.

Aqui, valerá a pena refletir sobre o modo como esta se constitui como uma força ideológica ou cultural, uma "retiologia", como lhe chama Pierre Musso (2006). A retiologia contemporânea é o vasto conjunto de representações, discursos, imagens e encenações utópicas produzidas a partir de reinterpretações epistemológicas e políticas do papel das redes técnicas em geral e das redes da Internet em particular. A rede é reificada e consequentemente fetichisada como o culminar de promessas herdadas do passado em que os aparelhos tecnológicos eram os meios instrumentais para as transformações no futuro das sociedades. Deslumbramo-nos com a "fada da eletricidade" e, recentemente, com as "redes inteligentes" (Musso, 2006):

"A retiologia é uma ideologia com aspirações utópicas, que se limita ao fetichismo das redes técnicas, especialmente a Internet. Quer se trate de ficção literária, futurologia ou análise socioeconómica da "sociedade em rede", a retiologia está constantemente a anunciar "revoluções"sócio-técnicas. Desta forma, alivia as utopias sociais e políticas do seu pesado fardo transferindo-as para a utopia tecnológica, que tem a vantagem de se materializar sempre" (Musso, 2016: 63). 
Na sua introdução ao trabalho de Musso e dos filósofos franceses na linha de Saint Simon, José Luis Garcia diz-nos que

"no pensamento progressista do século XVIII e XIX, os seres humanos procuraram domesticar a natureza através da tecnologia para a colocar ao seu serviço. Eles não estavam subordinados à tecnologia, uma situação que o crescente aumento do controlo sobre o mundo natural graças às tecnologias do século XX e início do século XXI se arriscam a trazer-nos. A escala sem precedentes e os termos desse domínio sobre a natureza sugerem uma tentativa de desacoplar os seres humanos do mundo natural e a criação de novos contextos, não só culturalmente, mas para a própria vida. Este processo transforma os seres humanos quer em demiurgos, quer em subordinados dos sistemas tecnológicos que criaram" (Garcia, 2016: 11).

Garcia lembra-nos, ainda, que precisamos de refletir sobre a complexa interação entre política, e ciência e tecnologia. Estas duas últimas, especialmente quando associadas à indústria, provocam transformações importantes no nosso quotidiano, nas nossas formas de pensar e no poder na vida social; pelo seu lado, a esfera política, consciente das possibilidades da ciência e da tecnologia, procura submetê-la a diretrizes que satisfazem os seus modos de compreender a sociedade, os seus interesses políticos, económicos e militares ou outros (Garcia, 2016: 12).

\section{A Bolha do pós-materialismo}

Entre o idealismo programático habermasiano da Modernidade e as ilusões pós-modernas que revimos atrás, encontra-se a ideia de "entangled modernities" onde a Modernidade se constitui como "uma conceção temporal que olha para a frente para este futuro mundano, aberto, atingível, ou passível de construção (...) A modernidade neste sentido não é, por si só, designada como um período cronológico particular ou qualquer forma institucional particular. Em princípio, diferentes períodos de modernidade, seguidos de des-modernização ou re-tradicionalização, são concebíveis" (Therborn 2003: p. 294).

É também no seio dessa modernidade que podemos encontrar o caminho que o pós-materialismo fez nas últimas décadas. Ronald Inglehart e Pippa Norris, que têm escrito sobre este tema, colocam-no com uma crueza certeira: "O pós-materialismo acabou por se tornar o seu próprio coveiro“. A ascensão do pós-materialismo, escrevem,

"trouxe um declínio no voto das classes sociais, prejudicando os partidos de esquerda da classe operária que tinham implementado políticas redistributivas durante a maior parte do século XX. Além disso, as novas questões não-económicas introduzidas pelos pós-materialistas obscureceram as clássicas questões económicas esquerda-direita, afastando a atenção da redistribuição para as questões culturais, abrindo caminho para um aumento da desigualdade" (2017: 444).

O que está em causa, então, é a mudança de uma política baseada nas classes para uma política de valores (culturais e identitários), o que pode deitar uma nova luz sobre os resultados eleitorais de ambos os lados do Atlântico.

O apoio aos partidos autoritários populistas é motivado por uma reação contra as mudanças culturais ligadas ao aumento dos valores pós-materialistas e de auto-expressão, muito mais do que 
por fatores económicos. A causa próxima do voto populista é a ansiedade gerada pelas mudanças culturais e por um afluxo de estrangeiros que corrói as normas culturais tradicionais aprendidas e conhecidas como "as nossas". Por isso, o principal tema comum de partidos populistas autoritários em ambos os lados do Atlântico é uma reação contra a imigração e a mudança cultural. Mas, embora a causa imediata do voto populista seja uma reação cultural, o seu elevado nível de votação reflete a diminuição da segurança económica e o aumento da desigualdade económica que muitos autores enfatizaram.

Quando Trump prometeu "voltar a fazer da América um grande país" estava simplesmente a prometer fazer da América um país como era no passado, onde não apenas os valores tradicionais eram mais fortes, mas também onde os níveis de desigualdade entre as classes sociais não eram tão gritantes. A sua frase populista dirigia-se, com mestria, à nostalgia de um passado retrógrado, mas menos desigual, pelo menos para uma certa classe operária/média branca que, nos últimos anos, se viu afetada também uma grande crise de desemprego e de problemas como a crise dos opioides que tradicionalmente afetavam mais os negros americanos. Também aqueles a quem o desemprego, a falta de perspetivas e o progressivo desmantelamento do estado social na Grã-Bretanha, na Alemanha e um pouco por toda a Europa, se deixaram seduzir por discursos "alternativos" que surgiram precisamente como uma crítica aos poderes instalados. É, então, também na crise do pós-materialismo que o populismo encontra um dos seus "ganchos" que ganham um eco muito particular nas novas tecnologias da comunicação, pelo que os dois conceitos e a sua ligação à comunicação deverão ser estudados nas suas múltiplas conexões.

Um contributo para esse estudo é o trabalho de Claudia Alvares e Peter Dahlgren (2016) que têm um importante trabalho de reflexão sobre a questão do populismo (um "significante vazio"?), propondo um programa de pesquisa sobre a sua ligação aos media.

E, com efeito, perfurar a bolha do pós-materialismo é também compreender bem de que modo a comunicação pode fazer a ponte entre ansiedades culturais, políticas populistas, tecnologias predadoras e a mobilização política que molda a ascensão e a queda da desigualdade.

\section{Conclusão}

Reunindo alguns dos vários elementos de crítica que constituem as nossas bolhas de verdade, Simon Susen (2015: 280) diz que

"Conceber a era contemporânea como uma era pós-utópica significa que é impossível explorar a medida em que, pelo menos a longo prazo, pode haver - e, talvez, haja - espaço para alternativas viáveis à hegemonia da sociedade capitalista. Celebrar a diferença e transformála num campo de batalha político significa correr o risco de reproduzir a lógica totalizante da busca pela universalidade em nome das lutas sociais preocupadas com o reconhecimento e o desconhecimento das especificidades culturais".

A estas bolhas de verdade se juntam muitas outras que fragmentam a nossa vida política, cultural e mediática. Mas o fundo sobre a qual elas pairam tem demasiados antecedentes para que o possamos ingenuamente considerar o fenómeno da pós-verdade como "novo". Assoberbadas por décadas de spin político, de mentiras totalitárias, de hegemonias que nos cimentam e de discursos 
neo-liberais que nos interpelam, talvez as distopias que fazem parte da nossa cultura pareçam cada vez mais reais. Mas, como diz Shirley Neuman (2006: 865) a propósito do romance de Atwood, "implícita em cada distopia existe uma utopia".

É certo que talvez não possamos partilhar da magnífica confiança que John Milton tinha na verdade e que expressou em Areopagítica, quando redigida em 1644:

"Que a verdade e a impostura se digladiem. Quem jamais ouviu dizer que a verdade perdesse num confronto em campo livre e aberto? (...) Ela não precisa de políticas, nem de estratagemas, nem de autorizações para se tornar vitoriosa; esses são ardis e obstáculos que o erro usa contra o seu poder" (1644/ 2009: 173-175).

Mas se Milton hoje nos impressiona pela sua candura, ainda há muito que podemos fazer para tornar a luta de que ele fala justa e aberta. Se abandonarmos o projeto de oferecer razões finais e uma lógica epistémica universal de padrões objetivos, podemos estar em melhor posição para reconhecer a complexidade de realidades material e simbolicamente diferenciadas, mas estaremos igualmente desprovidas do racional crítico para prosseguir com reivindicações válidas de verdade que precisam de constituir a base do nosso sentido de justiça solidária e aberta, na contestação sistemática da falsidade, dos interesses particularistas que servem a acumulação de capital e as lógicas neoliberais.

Creio que a reconciliação entre os dois objetivos não é impossível. E, sugiro, uma das coisas que podemos fazer é ir perfurando criticamente cada uma destas bolhas para que "tudo o que é bullshit se desfaça no ar".

\section{Referências}

Alvares, C. \& Dahlgren, P. (2016). Populism, extremism and media: mapping an uncertain terrain. European Journal of Communication, 31(1), 46-57.

Atwood, M. (1985/2013). The handmaid's tale. (trad. para língua portuguesa como A História de Uma Serva, ed. Bertrand). Toronto: Seal.

Baudrillard, J. (1991/1981). Simulacros e simulação. Lisboa: Relógio D’água.

Bauman, Z. (1999). Modernidade e ambivalência. Rio de Janeiro: Zahar.

Fallows, J. (2012). Bit by bit it takes shape: media evolution for the 'post-truth' Age. The Atlantic, Setembro, (4).

Fallows, J. (2017). With such a people you can then do what you please. The Atlantic, Fevereiro (21).

Foucault, M. (1976/2000). Truth and power. In J. D. Faubion (ed.), Power: essential works of Foucault, 1954-1984, vol. 3 (pp. 111-133). New York, NY: New Press.

Fraser, N. (2016). Progressive neoliberalism versus reactionary populism: a choice that feminists should refuse. NORA - Nordic Journal of Feminist and Gender Research, 24(4), 281-284.

Garcia, J. L. (2016). Introduction: towards a critical philosophy of networks - reflections on the perspective of Pierre Musso. In J. L. Garcia (org.), Pierre Musso and the network society. From Saint-Simonianism to the Internet. Springer. 
Habermas, J. (1981). Modernity versus postmodernity. New German Critique, (22), 3-14.

Habermas, J. (2006). Political communication in media society: does democracy still enjoy an epistemic dimension? The impact of normative theory on empirical research". Communication Theory, 16(4), 411-426.

Habermas, J. (2007). How to save the quality press?. Süddeutsche Zeitung, 16 May, (trad. para inglês disponível em: www.signandsight.com/features/1349.html)

Howell, E. H. (2009). Constructions and reconstructions: feminism, postmodernism, and the handmaid's tale. Concept, [S.1.], 33.

Inglehart, R. \& Norris, P. (2017). Trump and the xenophobic populist parties: the silent revolution in reverse. Perspectives on Politics, 15(2), 443-454.

Lyotard, J.-F. (1989). A Condição Pós-Moderna. Lisboa: Gradiva.

Milton, J. (1644/2009). Areopagítica. Discurso sobre a liberdade de expressão. Edições Almedina.

Musso, P. (2006). Ciberespaço, figura reticular da utopia tecnológica. In D. Moraes (org.), Sociedade midiatizada. Rio de Janeiro: Mauad.

Musso, P. (2016). Network ideology: from saint-simonianism to the internet. In J. L. Garcia (org.), Pierre Musso and the Network society from Saint-Simonianism to the Internet. Springer.

Neuman, S. (2006). 'Just a Backlash': Margaret Atwood, feminism, and the handmaid's tale. University of Toronto Quarterly, 75(3), 857-868.

Pariser, E. (2011). The filter bubble: how the new personalized web is changing what we read and how we think. Penguin Books.

Postman, A. (2017). My dad predicted Trump in 1985 - it's not Orwell, he warned, it's Brave New World. The Guardian, 2 fevereiro 2017.

Postman, N. (2005). Amusing ourselves to death: public discourse in the age of show business. 20 anv. ed. New York: Penguin.

Stein, K. (2001). Margaret Atwood's modest proposal: the handmaid's tale. In H. Bloom (ed.), Margaret Atwood's the handmaid's tale (pp. 127-140). Broomall: Chelsea House Publishers.

Sunstein, C. R. (2001). Republic.com. Princeton, NJ: Princeton University Press.

Susen, S. (2015). The 'postmodern turn' in the social sciences. New York: Palgrave Macmillan.

Therborn, G. (2003). Entangled modernities. European Journal of Social Theory, 6(3), 293-305.

Tolan, F. (2007). Margaret Atwood: feminism and fiction. Amsterdam: Rodopi. 